\title{
Impacto da pandemia do SARS-COV-2 na educação médica: migração "compulsória" para o modelo remoto, uma visão preliminar de gestores da educação médica
}

\author{
Impact of SARS-COV-2 pandemic on medical education: \\ "compulsory" migration for elearning modality, \\ preliminary insights from medical education managers
}

\section{Luiz Fernando Quintanilha' (1) \\ Katia de Miranda Avena ${ }^{2}$ (1) Lucélia Batista Neves Cunha Magalhães ${ }^{3}$ (1) Bruno de Bezerril Andrade 4 (1)}

\author{
'Centro Universitário UniFTC, Universidade Salvador (Salvador). Bahia, Brasil. contato@quintanilhaeducacao.com \\ ${ }^{2-3}$ Centro Universitário UniFTC (Salvador). Bahia, Brasil. katiaavena@hotmail.com, luceliamagalhaes@terra.com.br \\ ${ }^{4}$ Autor para correspondência. Centro Universitário UniFTC, Universidade Salvador, Escola Bahiana de Medicina e Saúde Pública, \\ Fundação Oswaldo Cruz (Salvador). Bahia, Brasil. bbezerril.ssa@ftc.br
}

RESUMO | INTRODUÇão: A pandemia por SARS-CoV-2 impactou os modelos educacionais ofertados nos cursos de Medicina. Nesse contexto, com a autorização para oferta de disciplinas remotamente, evidencia-se uma aceleração sem precedentes na migração do modelo presencial para ensino remoto, o que já vinha ocorrendo gradativamente no sistema de educação superior brasileiro. Devido ao isolamento social para enfrentamento da crise, este modelo está sendo aplicado integralmente em muitas Instituições de Ensino Superior (IES) do país, podendo repercutir em mudanças metodológicas na educação médica. OBJETIVOS: Discutir o impacto da pandemia do SARS-CoV-2 na educação médica, analisando a migração para o modelo remoto. MÉTODO: Baseado na experiência dos autores na gestão da educação médica, foi realizada uma reflexão a partir de reuniões gerenciais de duas IES privadas. RESULTADOS: O contexto de pandemia global promoveu impactos no ensino no âmbito do corpo discente, docente e IES. Os altos investimentos na migração do modelo de ensino e a alta taxa de evasão vêm repercutindo na suspensão de contratos de docentes de IES privadas. A desigualdade de acesso tecnológico, ambientes não propícios e a má qualidade da telefonia/internet no país podem impactar no desempenho acadêmico. CONCLUSÕES: É inegável que a educação médica está sendo profundamente transformada por essa crise global de saúde. Entretanto, ainda é cedo para afirmar com segurança o tamanho desse impacto. Futuramente, será necessário adaptar o conceito de Ensino Médico baseado em evidências para avaliar com clareza as repercussões práticas dessa pandemia no ensino da Medicina.

PALAVRAS-CHAVE: Coronavírus. Educação a Distância. Educação Médica.
ABSTRACT | INTRODUCTION: The SARS-CoV-2 pandemic affected the educational models offered in medical courses. In this context, with the authorization to offer courses remotely, there is an unprecedented acceleration in the migration from the traditional model to the eLearning model, which was already occurring gradually in the Brazilian higher education system. Due to the social isolation to face the crisis, this model is being applied in full in many Higher-educational institutions (HEls) in the country and may have repercussions on methodological changes in medical education. OBJECTIVES: To discuss the impact of the SARS-CoV-2 pandemic on medical education, analyzing the migration to eLearning Modality. METHOD: A reflection was made from management meetings at two private universities based on the authors' experience in medical education management. RESULTS: The global pandemic context has impacted teaching within the scope of students, professors, and HEls. The high investments in the migration of the teaching model and the high dropout rate have impacted the suspension of contracts for teachers from private HEls. The inequality of technological access, unsuitable environments, and the poor quality of telephony/internet in the country can impact on academic performance. CONCLUSIONS: It is undeniable that medical education is suffering a profound transformation by this global health crisis. However, it is too early to say with certainty the size of this impact. In the future, it will be necessary to adapt the concept of evidencebased medical education to assess the practical repercussions of this pandemic in medical education.

KEYWORDS: Coronavirus. eLearning. Medical Education. 


\section{Contexto da situação}

A crise global ocasionada pela pandemia do SARSCoV-2 vem impactando as sociedades em todo o mundo em diversos aspectos. As mudanças na economia, relações profissionais, familiares, saúde e educação têm sido intensamente discutidas. Todas essas esferas já sofreram impactos importantes e, certamente, seguirão sendo impactadas no desenrolar da crise e por um período considerável após o controle da pandemia.

Frente ao cenário pandêmico, os Ministérios da Educação (MEC) e da Saúde (MS) vêm capitaneando uma série de medidas cujos impactos refletem em toda a sociedade brasileira, direta ou indiretamente. No âmbito da educação médica, por exemplo, as aulas remotas do primeiro ao quarto ano no curso de graduação em Medicina, excetuando-se, por enquanto, as práticas profissionais de estágios e laboratório, foram legalmente viabilizadas. Isso gera mudanças significativas na educação médica, podendo influenciar enormemente o modus operandi dos cursos médicos e a atuação dos principais atores envolvidos em um futuro muito próximo.

No âmbito educacional, o cenário de adaptação à crise, portanto, deixará de ser exclusivamente emergencial e impactará na forma de gerenciamento da educação médica no país, incluindo a adoção de ensino remoto em maior escala e todas as suas implicações práticas. Nesse contexto, a partir da perspectiva de gestores de dois cursos médicos privados no estado da Bahia, este artigo se propõe a discutir o impacto da pandemia do SARS-CoV-2 na educação médica, analisando a migração "compulsória" para o ensino remoto, as estratégias no âmbito das mudanças da migração de modelos de ensino e os impactos no modus operandi de escolas médicas no Brasil.

\section{Sumário do trabalho}

Baseado na experiência dos autores em gestão educacional na área médica e considerando o momento de crise sanitária com impactos profundos no setor educacional, foi realizado um relato de caso a partir de reuniões gerenciais de duas IES privadas do estado da Bahia, realizadas de março a junho de 2020. Essas reuniões ocorreram semanalmente e, de maneira extraordinária, em momentos de demandas urgentes com a presença dos membros do Núcleo Docente Estruturante (NDE), além de representantes da mantenedora.

A partir dessas reuniões, o grupo de autores se reuniu para o desenvolvimento do presente trabalho com o objetivo de discutir o impacto da pandemia do SARSCoV-2 na educação médica, analisando a migração "compulsória" para o modelo remoto e suas perspectivas a curto e médio prazos para gestores, professores e estudantes, principais atores nesse processo. Neste âmbito, foram destacados os movimentos históricos pré-pandemia e pós-pandemia e, a partir disso, a construção de reflexões acerca dos impactos dessas mudanças na visão dos autores.

Pelas características da análise, porém, este trabalho tem uma abrangência nacional por descrever o cenário atual do ensino médico baseado nas resoluções do MEC e MS e realizar prognósticos pautados em observações e evidências atuais no contexto do ensino remoto em cursos de graduação em Medicina.

\section{Sumário dos resultados}

\section{Aspectos gerais da educação superior no Brasil}

Segundo o Censo da educação superior publicado pelo Instituto Nacional de Estudos e Pesquisas Educacionais Anísio Teixeira (INEP) em 2019, a média de idade dos docentes atuantes nas instituições de ensino superior (IES) públicas e privadas é de 38 anos. Esta faixa etária supõe que esses professores tiveram contato com avanços tecnológicos de maneira incipiente e foram educados em modelos tradicionais de ensino. Já os estudantes que adentram as salas de aula do ensino superior atualmente apresentam média de idade de 19 anos (ensino presencial) e 21 anos (ensino a distância). ${ }^{1}$ São, portanto, pertencentes à chamada geração-Z, nativos digitais, globalizados, acostumados a ambientes interativos e, por essas características, apresentam muita dificuldade de pertencimento aos modelos mais tradicionais de ensino, ao passo que são muito receptivos a novas estratégias de ensino-aprendizagem. ${ }^{2}$ Estudos recentes demonstraram que essa geração é altamente receptiva à utilização de ferramentas online e à inserção de metodologias ativas de ensino e, portanto, extremamente adaptáveis ao modelo remoto de ensino.3.4. Esta observação está de acordo com dados divulgados pela Associação Brasileira de 
Mantenedoras de Ensino Superior (ABMES) que constatam que, apesar da pandemia, houve um aumento substancial no número de estudantes que consideram ingressar no ensino superior no início de 2021. Além disso, a ABMES também projeta que o número de matrículas no ensino à distância superará o de matrículas no presencial antes do previsto e que o ensino híbrido seguirá com forte tendência de expansão. ${ }^{6}$

\section{Ensino a Distância (EaD) no ensino superior brasileiro}

Apesar de não serem sinônimos e possuírem características que os diferem, no presente trabalho, os termos "EaD" e "ensino remoto" são utilizados como tal, pelas suas similaridades práticas no que tange ao uso da tecnologia no processo de ensino-aprendizagem. Entende-se por EaD a modalidade educacional na qual a mediação didático-pedagógica nos processos de ensino-aprendizagem ocorre por meio de "pontes" tecnológicas entre o professor e os alunos que estão geograficamente separados. ${ }^{\text {. Temporalmente, esta }}$ modalidade pode ser síncrona ou assíncrona, dependendo se a interação ocorre em tempo real ou não.

A modalidade $\mathrm{EaD}$ cresce em alinhamento com as mudanças nos contextos sociais, como o acesso à internet, a escassez de tempo livre e outros fatores relacionados à modernidade. Também por conta das características do alunado, o EaD tem ganhado força no país nos últimos anos. De 2008 a 2018, o número de ingressantes em cursos de graduação na modalidade EaD saltou de 463.093 para 1.373.321 alunos, ou seja, um aumento expressivo de quase três vezes que permite previsões de que nos próximos anos esta modalidade superará o número de matrículas no modelo presencial. $\underline{6}$

Especificamente na graduação em Medicina, ainda há restrições, como será demonstrado adiante. Por outro lado, para a educação continuada, a existência de cursos à distância sempre foi considerada como benéfica e com potencial de atingir profissionais residentes distante dos grandes centros e/ou com escassez de tempo. ${ }^{910}$ Atualmente, existe no país um grande leque de opções de cursos de atualização abarcados por renomadas instituições de ensino e pesquisa ofertados nesta modalidade.
São relatadas inúmeras vantagens neste modelo de ensino tais como flexibilidade, universalização no acesso, redução de custos e alcance geográfico. Todos esses fatores são considerados como características positivas do modelo $\mathrm{EaD}$, o que faz com que essa modalidade de ensino tenha percepções positivas e ganhe cada vez mais adeptos na Medicina e em outros cursos de saúde. ${ }^{11}$ Porém, apesar do aumento substancial de cursos, a modalidade EaD no Brasil ainda carece de melhor preparação dos professores e tutores envolvidos no processo ${ }^{12,13}$, além de ainda ser identificada alguma resistência por parte dos

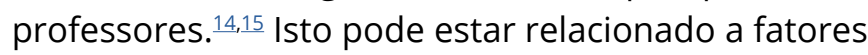
como formação tradicional, resistência e receio a mudanças, escassez de recursos, de tempo para treinamentos, e inabilidade com recursos tecnológicos. $\frac{15}{5}$

\section{Regulamentação do EaD}

O MEC tem sido claramente favorável à expansão do EaD no país. O decreto 9.057/2017, por exemplo, permite que as IES ofertem exclusivamente cursos de graduação e pós-graduação lato-sensu a distância sem a necessidade de ofertar, simultaneamente, cursos presenciais. Em 2018 a oferta de cursos à distância contemplou, também, a programas de pós-graduação stricto-sensu (Mestrado e Doutorado) acadêmicos e profissionais.

A ampliação de vagas EaD universaliza o acesso, permite que estudantes do interior possam fazer seus cursos de graduação e pós-graduação e, com isso, aumenta a possibilidade de educação continuada em locais mais distantes, além de facilitar o atingimento das metas educacionais no país no âmbito das matrículas na educação superior. Outro indício nesta direção veio com uma recente resolução do MEC aumentando o limite de oferta de disciplinas na modalidade a distância para cursos de graduação. A portaria 1.428/2018 dobrou o limite, de $20 \%$ para $40 \%$, para a oferta de disciplinas EaD em cursos presenciais. De acordo com esta portaria, porém, esta regra não se aplica aos cursos da área de saúde. Não se sabe como este cenário vai evoluir no país nem a velocidade com que isso vai ocorrer, porém é coerente pensar, pelas evidências, que haverá um aumento generalizado da oferta desta modalidade de ensino, além da qualidade e eficiência das tecnologias utilizadas por ela. A migração para o modelo remoto na atual crise do SARS-CoV-2 pode contribuir imensamente para este cenário. 


\section{Quais lições foram aprendidas}

\section{O impacto da pandemia na educação médica}

A pandemia do novo coronavírus (SARS-CoV-2) vem impondo mudanças nos relacionamentos nas esferas social, familiar, relações de trabalho, saúde e educação. Neste atual cenário, o MEC autorizou a oferta de ensino remoto para as IES, porém proibiu o curso de Medicina de fazê-lo. Pouco tempo depois, mudou de posicionamento e permitiu que o curso de Medicina oferecesse a modalidade online nas disciplinas teórico-cognitivas do primeiro ao quarto ano.

Dessa forma, as IES, especialmente as privadas, majoritárias no país, conseguiram garantir o cumprimento do cronograma acadêmico e a entrada de recursos provenientes das mensalidades e matrículas. Dados do Sindicato das Entidades Mantenedoras de Estabelecimentos de Ensino Superior no Estado de São Paulo (Semesp) apontavam que, em agosto de 2020,99\% das IES privadas já haviam migrado para o ensino remoto. ${ }^{16}$ Por sua vez, apesar das controvérsias geradas, os estudantes tiveram garantido o direito de concluir o semestre, em geral, sem atrasos. Contudo, somente o conteúdo teórico de suas disciplinas foram contemplados, pois, apesar de já haver ferramentas virtuais alternativas $\frac{17}{17}$, até o momento da elaboração deste trabalho está vetada a utilização delas para disciplinas que contemplem atividades práticas no plano pedagógico.

Ao analisar o impacto no corpo docente, observa-se que os professores, majoritariamente acostumados com o modelo presencial de ensino, tiveram que se adaptar rapidamente e de maneira compulsória a este novo formato. Sem tempo para a ambientação e o treinamento das "novas" tecnologias, notou-se claramente um forte movimento das IES no sentido de capacitar prontamente o seu corpo docente para a virtualização das atividades. As ferramentas para isso, de maneira geral, já existiam, mas não eram utilizadas, ou eram subaproveitadas. Assim, o modelo remoto que vinha ganhando, de maneira gradual, força em números, atingiu, repentinamente, a maioria do ensino médico privado ofertado nos principais centros do país ${ }^{16}$ e os professores tiveram que, repentinamente, migrar todo o seu material de aula para uma ou mais plataformas online. Nesse sentido, instituições que já haviam feito essa migração sofreram menos impactos, visto que sua comunidade acadêmica já estava ambientada, ao menos parcialmente, com o modelo a distância.

Por outro lado, houve um impacto mais cruel para o corpo docente que se revelou mais visivelmente na virada do semestre letivo. Além do já documentado impacto na qualidade de vida ${ }^{18,19}$, devido à possibilidade de manutenção de aulas remotas regulamentada pelo MEC, com os altos investimentos na migração do modelo de ensino e a alta taxa de evasão na modalidade a distância ${ }^{20,21}$, as IES privadas efetivaram a suspensão de contratos e realizaram demissões de muitos professores em todo o país.

Já as IES públicas pausaram, majoritariamente, suas atividades e seus professores se viram impedidos de lecionar. Muitos foram os argumentos utilizados para a paralisação, sendo o mais difundido a desigualdade de acesso tecnológico de suas comunidades acadêmicas. Mesmo no curso de Medicina, normalmente com características sociais mais abastadas, estudos demonstram falta de acesso à internet em casa e ambientes não propícios ao melhor desempenho discente. ${ }^{22,23}$ Soma-se a isso, a sabida má qualidade da telefonia e internet no país. Neste cenário, algumas instituições mitigaram essas desigualdades com estratégias diversas como a oferta de chips, o empréstimo de notebooks para os estudantes com maiores dificuldades e a cessão de espaços em seus campi com hora marcada.

\section{Perspectivas futuras nas escolas médicas}

Assim como os principais centros do mundo já vêm praticando ensino através de pontes tecnológicas, o MEC vem incentivando a modalidade EaD há algum tempo. Com as mudanças impostas pela pandemia, boa parte dos professores se tornaram, obrigatoriamente, mais habituados com a modalidade. Nesse contexto, as perspectivas futuras apontam para a utilização cada vez maior dessa modalidade pelas IES. Este é o cenário que os professores e estudantes devem se adaptar.

Para as IES, investir no ensino remoto e a distância é vantajoso pela possibilidade de redução de custos e maiores ganhos ao escalonar sua presença regional. Para os alunos, apesar das desvantagens supracitadas, é mais cômodo, econômico e habitual, pois são ferramentas que já fazem parte do dia-a-dia dessa geração. Neste âmbito, este modelo traz flexibilidade, economia, respeita o tempo de aprendizado do 
estudante sem, contudo, se bem organizado, perder interatividade.

Já para os professores, apesar dos benefícios de terem suas aulas gravadas e/ou poderem lecionar de qualquer local, o fato de poder ser utilizada de maneira exponencial traz uma consequência preocupante: a dispensabilidade da figura do professor. Aqui não está sendo afirmado, de maneira alguma, que o professor não é essencial no processo, mas que um único professor pode ser o responsável pelas aulas de determinada unidade curricular para um número maior de estudantes/turmas, o que, presencialmente, seria inviável. Esta configuração pode, portanto, gerar dispensas de outros profissionais envolvidos na mesma unidade curricular, fenômeno que já se apresenta claramente neste momento.

Apesar das vantagens já descritas, muito ainda se discute acerca da qualidade do ensino remoto e a distância. Como exemplo, a utilização de metodologias ativas, tão debatidas e utilizadas atualmente, carece de melhores adaptações e evidências de eficácia neste modelo. A avaliação a distância é outro entrave que precisa ser mais bem discutido. Por outro lado, apesar de haver necessidade de estudos mais aprofundados, amplos e de melhor qualidade metodológica sobre o tema ${ }^{24}$, a literatura traz evidências de igual eficácia ou até mesmo superior ao ensino presencial desde que haja utilização de métodos que permitam o alcance dos objetivos da disciplina/curso, haja interação dos estudantes e feedback do professor. ${ }^{25}$ As travas de qualidade que ainda possam existir provavelmente serão solucionadas com muita brevidade conforme a modalidade a distância vá ganhando mais adeptos, a concorrência aumente e as tecnologias evoluam. Neste sentido, destacam-se como fatores desfavoráveis a universalização deste modelo no Brasil, problemas de acesso (conexão) e inabilidade dos professores e tutores com as ferramentas tecnológicas utilizadas.

Esta mudança de paradigma educacional vivenciada, imposta e acelerada pela pandemia vigente, pode, portanto, significar mudanças substanciais na relação de trabalho. Migração para o modelo de trabalho por contrato ou pessoa jurídica? Oportunidades para os professores desenvolverem novas habilidades e ferramentas com retorno financeiro? Ainda não é possível afirmar. Mas já passou da hora da reflexão acerca desse tema.

\section{Conclusões}

É possível que, excetuando as unidades curriculares com óbvia necessidade de conteúdo prático e, portanto, com atividade presencial e de laboratório indispensáveis, outras disciplinas possam migrar para o modelo remoto em um curto espaço de tempo, com incremento de qualidade constante devido a disponibilização de novas ferramentas tecnológicas, adaptação das IES e capacitação docente. Assim como ocorreu em outras profissões devido a inovação tecnológica, chegou a hora dos professores passarem por transformações profundas na sua configuração de trabalho. Isso vai causar demissões e redução de proventos? Não é possível afirmar. Pode abrir novas perspectivas? Ninguém sabe ao certo. Impactará na qualidade dos formandos? Ainda é cedo para afirmar, pois, apesar de estar em expansão, ainda há poucos estudos na área.

É inegável que a educação médica está sendo profundamente transformada a partir dessa crise global de saúde. Entretanto, ainda é cedo para afirmar com segurança o tamanho desse impacto. Futuramente, será necessário adaptar o conceito de Ensino Médico baseado em evidências para avaliar com clareza as repercussões práticas dessa pandemia no ensino da Medicina.

\section{Contribuições dos autores}

Todos os autores contribuíram na concepção, desenvolvimento e redação do artigo científico, tendo aprovado a versão final encaminhada para publicação.

\section{Conflitos de interesses}

Nenhum conflito financeiro, legal ou político envolvendo terceiros (governo, empresas e fundações privadas, etc.) foi declarado para nenhum aspecto do trabalho submetido (incluindo, mas não se limitando a subvenções e financiamentos, participação em conselho consultivo, desenho de estudo, preparação de manuscrito, análise estatística, etc.).

\section{Referências}

1. Instituto Nacional de Estudos e Pesquisas Educacionais Anísio Teixeira (Brasil). Censo da Educação Superior 2018: notas estatísticas [Internet]. Brasilia: Inep/MEC; 2019. Disponível em: http://download.inep.gov.br/educacao_superior/censo_superior/ documentos/2019/censo_da_educacao_superior_2018-notas. estatisticas.pdf 
2. McCrindle M. The ABC of XYZ: Understanding the Global Generations. 3a. ed. Bella Vista, NSW: McCrindle Research Pty Ltd; 2014. 288 p.

3. Quintanilha LF. Inovação pedagógica universitária mediada pelo Facebook e YouTube: uma experiência de ensino-aprendizagem direcionado à geração-Z. Educ rev. 2017;(65):249-63. https://doi. org/10.1590/0104-4060.50027

4. Quintanilha LF, Costa GN, Coutinho MR. Medical student perceptions about active methodologies in the study of physiology in medical schools in Salvador, Brazil. Adv Physiol Educ. 2018;42(4):693-6. https://doi.org/10.1152/advan.00105.2018

5. ABMES. Melhora a percepção dos jovens que pretendem começar uma faculdade em 2021 [Internet]. Brasília: Associação Brasileira de Mantenedoras do Ensino Superior; 2020. [citado em 2020 dez 25]. Disponível em: https://abmes.org.br/noticias/ detalhe/4097/melhora-a-percepcao-dos-jovens-que-pretendemcomecar-uma-faculdade-em-2021

6. ABMES. Em 2022, curso on-line vai superar presencial [Internet]. Brasília: Associação Brasileira de Mantenedoras do Ensino Superior; 2020 [citado em 2020 dez 25]. Disponível em: https://abmes.org.br/noticias/detalhe/3806

7. Alves L. Educação a distância: conceitos e história no Brasil e no mundo. Rev Bras Aprend Aberta. 2011;10. https://doi. org/10.17143/rbaad.v10i0.235

8. Silva FNMD, Meirelles FDS. Influência da tecnologia interativa síncrona e da adaptação metodológica sobre a intenção de continuidade de uso da educação a distância [Internet]. RELATEC Rev Latinoam Tecnol Educ. 2015;14(3):49-62. Disponível em: http://hdl.handle.net/10438/23605

9. Leite MTM, Carlini AL, Ramos MP, Sigulem D. Educação médica continuada online: potencial e desafios no cenário brasileiro. Rev Bras Educ Med. 2010;34(1):141-9. https://doi.org/10.1590/S0100$\underline{55022010000100017}$

10. Oliveira AEF, Ferreira EB, Sousa RR, Castro Junior EF, Maia MFL. Educação a distância e formação continuada: em busca de progressos para a saúde [Internet]. Rev Bras Educ Med. 2013;37(4):578-83. Disponível em: https://www.scielo.br/pdf/ rbem/v37n4/a14v37n4.pdf

11. Faleiro FRG, Salvago BM. Educação a Distância nos Cursos de Graduação em Odontologia no Brasil. Rev Bras Aprend Aberta. 2018;17(1). https://doi.org/10.17143/rbaad.v17i2.45

12. Lau FA, Mendes VF, Ventura AA, Bollela VR, Teixeira LAS. Implantação de Estratégias de Ensino à Distância durante o Internato: Desafios e Perspectivas. Rev Bras Educ Med. 2017;41(2):269-77. https://doi.org/10.1590/198152712015v41n2rb20160069
13. Pavanelo E, Krasilchik M, Germano JSE. Contribuições para Preparação do Professor na Educação a Distância. Rev Bras Aprend Aberta. 2018;17(1):e072. https://doi.org/10.17143/rbaad. v17i1.72

14. Patto MHS. O ensino a distância e a falência da educação. Educ Pesqui [Internet]. 2013;39(2):303-18. Disponível em: https:// www.scielo.br/pdf/ep/v39n2/a02v39n2.pdf

15. Silva AVM. Tecnologias e Educação: o discurso da UNESCO. Educ. 2019;44:e65. https://doi.org/10.5902/1984644437288

16. Semesp. Pesquisa do SEMESP revela que $99 \%$ das IES privadas migraram para o ensino remoto. Nas públicas, apenas 41,8\% [Internet]. Sindicato das Entidades Mantenedoras de Estabelecimentos de Ensino Superior no Estado de São Paulo [Internet]. São Paulo: Secretaria de Modalidades Especializadas de Educação; 2020. [citado em 2020 dez 25]. Disponível em: https:// www.semesp.org.br/imprensa/pesquisa-do-semesp-revela-que991-das-instituicoes-privadas-migraram-para-o-ensino-remotonas-publicas-apenas-418/

17. Silva JB, Bilessimo SMS, Scheffer GR, Silva IN. Laboratórios Remotos como Alternativa para Atividades Práticas em Cursos na Modalidade EAD. EaD em Foco. 2020;10(2):e810. https://doi. org/10.18264/eadf.v10i2.942

18. Oliveira GF, Alves MC, Costa CR, Silva AMS, Lofiego MCB, Oliveira VC, et al. Acolhimento psicológico durante o COVID-19: relato de experiência. Brazilian J Heal Rev. 2020;3(4):10070-9. https://doi.org/10.34119/bjhrv3n4-234

19. Araujo RM, Amato CAH, Martins VF, Eliseo MA, Silveira IF. COVID-19, Mudanças em Práticas Educacionais e a Percepção de Estresse por Docentes do Ensino Superior no Brasil. Revista Brasileira de Informática na Educação [Internet]. 2020;28:864-91. Disponível em: https://www.br-ie.org/pub/index.php/rbie/article/ download/v28p864/6744

20. Silva CMM, Rocha JV. Novas Tecnologias Aplicadas na EAD: um Estudo de Caso Sobre Retenção e Evasão Escolar no Ensino Superior. EaD em Foco. 2020;10(2):e919. https://doi.org/10.18264/ eadf.v10i2.919

21. Kowalski A, Mattar J, Barbosa LC, Branco LSA. Evasão no Ensino Superior a Distância: Revisão da Literatura em Língua Portuguesa. EaD em Foco. 2020;10(2):e983. https://doi. org/10.18264/eadf.v10i2.983

22. Cardoso Filho FAB, Magalhães JF, Silva KML, Pereira ISSD. Perfil do Estudante de Medicina da Universidade do Estado do Rio Grande do Norte (UERN), 2013. Rev. bras. educ. med. 2015;39(1):32-40. https://doi.org/10.1590/198152712015v39n1e01092014 
23. Rego RM, Marques NA, Monteiro PC, Oliveira CLB, Lins NAA, Caldas CAM. O perfil atual do estudante de Medicina e sua repercussão na vivência do curso. Para Res Med J. 2018;2(1-4):e05. http://dx.doi.org/10.4322/prmj.2018.005

24. Fernandes HL, Caron MF, Silva MAA. Apresentação do dossiê Educação e Mídias Digitais. Rev Eletrônica Educ. 2020;14(1-

5):3902002. https://doi.org/10.14244/198271993902
25. Fontaine G, Cossette S, Maheu-Cadotte MA, Mailhot T, Deschênes MF, Mathieu-Dupuis G, et al. Efficacy of adaptive e-learning for health professionals and students: A systematic review and meta-analysis. BMJ Open. 2019;9(8):e025252. https:// doi.org/10.1136/bmjopen-2018-025252 